Ursula G. Kyle

Philippe Jolliet

Laurence Genton

Christoph A. Meier

Nouri Mensi

Jean-Daniel Graf

Jean-Claude Chevrolet

Claude Pichard

\section{Clinical evaluation of hormonal stress state in medical ICU patients: a prospective blinded observational study}

Received: 18 March 2005

Accepted: 22 September 2005

Published online: 25 October 2005

(C) Springer-Verlag 2005

This work was supported by Foundation Nutrition 2000Plus

U. G. Kyle · L. Genton · C. Pichard (

Department of Nutrition,

Geneva University Hospital,

1211 Geneva, Switzerland

e-mail: claude.pichard@medecine.unige.ch

Tel.: +41-22-3729349

Fax: +41-223729363

P. Jolliet · J.-C. Chevrolet

Department of Medical Intensive Care Unit,

Geneva University Hospital,

1211 Geneva, Switzerland

C. A. Meier

Department of Endocrinology,

Geneva University Hospital,

1211 Geneva, Switzerland

N. Mensi - J.-D. Graf

Department of Clinical Chemistry,

Geneva University Hospital,

1211 Geneva, Switzerland

\begin{abstract}
Objective: To evaluate whether classification of patients as having low, moderate, or high stress based on clinical parameters is associated with plasma levels of stress hormone Design and setting: Prospective, blinded, observational study in an 18-bed medical ICU. Patients: Eighty-eight consecutive patients Interventions: Patients were classified as low $(n=28)$, moderate $(n=33)$ or high stress $(n=27)$ on days 0 and 3 of ICU stay, based on 1 point for each abnormal parameter: body temperature, heart rate, systemic arterial pressure, respiratory rate, physical agitation, presence of infection and catecholamine administration. The stress categories were: high: 4 points or more, moderate $2-3$ points, low 1 point. Plasma growth hormone $(\mathrm{GH})$, insulin-like growth factor 1 (IGF-1), insulin, glucagon, cortisol were measured on days 0 and 3. Measurements and results: Plasma cortisol and glucagon were signifi-
\end{abstract}

cantly higher and IGF-1 lower in high vs. low stress patients on days 0 and 3 . High stress patients were more likely to have high cortisol levels (odds ratio 5.8, confidence interval 1.8-18.9), high glucagon (8.7, 2.1$36.1)$, and low IGF-1 levels $(5.9,1.8$ 19.0) than low stress patients on day 0 . Moderate stress patients were also more likely to have high cortisol and glucagon levels than low stress patients. Insulin and GH did not differ significantly. Results were similar for day 3. Conclusions: Moderate and severe stress was significantly associated with high catabolic (cortisol, glucagon) and low anabolic (IGF-1) hormone levels. The hormonal stress level in ICU patients can be estimated from simple clinical parameters during routine clinical evaluation.

Keywords Growth hormone Insulin-like growth factor 1 . Cortisol · Glucagon · Insulin • Stress level

\section{Introduction}

Many intensive care unit (ICU) patients present with hypermetabolism and catabolic stress state which leads to major endogenous protein breakdown and is associated with respiratory and nonrespiratory muscle wasting [1]. Muscle mass wasting is accompanied by physical weakness with prolonged physical rehabilitation and/or an increased likelihood of difficult weaning from the ventilator. The latter increases the risk of nosocomial infections such as pneumonia which in turn is responsible for further catabolism.
Stress is defined as the effects produced when a stressor (such as trauma, injury, and infection) acts upon a structure, system or organism. When stress occurs in quantities that the system cannot handle, it produces pathological changes, including muscle catabolism [2]. Thus stress level is the main modulator of the catabolic process, which drives the progression of malnutrition and leads to impaired functional status. To minimize muscle wasting therapy should aim at identifying the level of hormonal stress. Since nutritional support is one of the therapeutic strategies to limit catabolism, timely intervention that is proportional to the stress level is desirable. 
Patients with a low stress level probably require standard nutritional support only, and support can be delayed 35 days, as recommended by the ESICM [3], but it should not be delayed in moderately and highly stressed patients with increased metabolic demands and compromised nutritional status. Early intervention in malnourished, elderly, and highly stressed patients is essential to prevent protein-energy malnutrition $[4,5]$ and major catabolism. The early detection of the stress level of ICU patients could prove valuable by allowing a timely intervention to promote anabolism and reduce catabolism.

Thus identifying hormonal stress is important. However, the tools necessary for the clinical evaluation of the stress level of ICU patients have so far not been defined. Traditionally, cortisol and glucagon have been used as indicators of hormonal stress. However, these measurements are complex, expensive, and not immediately available. For this reason we classified ICU patients into three stress categories (low, moderate, high) by using easily defined clinical parameters. We compared the clinical parameters to plasma hormone levels at admission and after 3 days in the ICU. The aim of this stress classification was to evaluate the level of catabolism without using labor- and cost-intensive investigations to determine whether nutritional support should be started early or later in moderately ill patients.

The aim of this prospective, blinded study was to evaluate whether the classification of patients as having low, moderate, or high stress levels based on easily obtainable clinical parameters is associated with the levels of catabolic (cortisol, glucagon) and anabolic hormones (growth hormone, GH); insulin-like growth factor 1, IGF1 ; insulin). This is a pilot study that requires further validation.

\section{Methods}

\section{Patients}

The study was approved by the Ethics Committee of the Internal Medicine Department. All patients admitted to the medical ICU were considered for inclusion unless they presented with any of the following exclusion criteria: preexisting renal failure (serum creatinine $\geq$ $300 \mathrm{mmol} / \mathrm{l}$ ), insulin-treated type 2 diabetes, pituitary, adrenal or thyroid insufficiency, and neuromuscular disease, including paralyzed patients. Patients who could not be included within $8 \mathrm{~h}$ after admission were also excluded. During a 1-month period 100 consecutive patients of 141 were included; 41 were excluded because they either did not meet inclusion criteria or they were not assessed within $8 \mathrm{~h}$ of admission to the ICU. Of the remaining 100 patients, 12 dropped out because of death $(n=3)$, transfer to the surgical ICU or non-ICU ward $(n=6)$ or missing values $(n=3)$. The study thus included 88
Table 1 Physical characteristics and diagnosis of study groups evaluated on day 0 (APACHE Acute Physiology and Chronic Health Evaluation, ARDS acute respiratory distress syndrome, $C O P D$ chronic obstructive pulmonary disease, SAPS Simplified Acute Physiology Score)

\begin{tabular}{llll}
\hline & $\begin{array}{l}\text { High } \\
(n=27)\end{array}$ & $\begin{array}{l}\text { Moderate } \\
(n=33)\end{array}$ & $\begin{array}{l}\text { Low } \\
(n=28)\end{array}$ \\
\hline Sex: M/F & $17 / 10$ & $20 / 13$ & $21 / 7$ \\
Age (years) & $61.3 \pm 16.7$ & $59.5 \pm 18.1$ & $57.4 \pm 18.1$ \\
Length of stay (days)** & $12.0 \pm 8.4$ & $6.0 \pm 4.7$ & $2.9 \pm 2.5$ \\
Geneva Clinical & $4.5 \pm 0.6$ & $2.7 \pm 0.5$ & $0.5 \pm 0.5$ \\
Assessment* & & & \\
APACHE II Score* & $12.8 \pm 4.3$ & $13.7 \pm 5.8$ & $6.7 \pm 3.5$ \\
SAPS* & $10.9 \pm 4.1$ & $10.5 \pm 4.3$ & $5.2 \pm 2.9$ \\
Body mass index & $24.4 \pm 6.2$ & $25.7 \pm 7.3$ & $27.1 \pm 6.2$ \\
Diagnosis & & & \\
Septic shock & 9 & - & - \\
ARDS & 5 & - & - \\
Cardiac arrest & - & 2 & - \\
Cardiogenic & & 3 & - \\
pulmonary edema & - & - & 5 \\
Myocardial infarction & - & - & 10 \\
Unstable angina & - & - & 6 \\
Myocarditis & 1 & 7 & 3 \\
Respiratory pathologies & 1 & 15 & 1 \\
COPD & 3 & 2 & - \\
Asthma & 2 & 3 & - \\
Liver failure & - & 1 & 3 \\
Other & & & \\
\hline
\end{tabular}

$* p<0.05$ (analysis of variance), $* * p<0.50$ (Kruskal-Wallis)

evaluable (aged 17-84 years). The main clinical characteristics and diagnoses are presented in Table 1. The stress-defined groups did not differ significantly in sex, age, body mass index, or standard blood chemistry test results. Of the patients in the high-stress group $74 \%$ were hospitalized because of septic shock, cardiac arrest, or acute respiratory distress syndrome. Moderate-stress patients were admitted to the ICU predominantly for respiratory insufficiency $(73 \%)$. Low-stress patients were hospitalized mostly for myocardial infarction and angina $(75 \%)$. A bed scale was used to determine body weight with a precision of $\pm 50 \mathrm{~g}$ and body height was measured with a precision of $\pm 0.5 \mathrm{~cm}$. Patients received nutritional support (oral, enteral, parenteral) according to our standard ICU protocol. Nutritional intake was progressively increased according to predicted requirements and tolerance.

\section{Clinical evaluation}

Patients were included in the study within $8 \mathrm{~h}$ of ICU admission, when the initial assessment was made. A second evaluation was performed $72 \mathrm{~h}$ later. Clinical diagnosis on admission was recorded and clinical scoring of the hormonal stress level of the patients was performed by one of two authors (P.J. and J.C.C.), both senior certified ICU physicians. Both clinicians and laboratory techni- 
cians were blinded to each others' results until the end of the study. Patients were classified as low, moderate, or high stress. Classification of stress categories was based on the following clinical criteria: (a) body temperature $36^{\circ}$ or below or $38^{\circ} \mathrm{C}$ or above; (b) heart rate $100 / \mathrm{min}$ or higher; (c) mean systemic arterial pressure 60 or lower or $120 \mathrm{mmHg}$ or higher; (d) respiratory rate $20 / \mathrm{min}$ or less; (e) presence of infection, defined as a clear clinical source and/or positive body fluids cultures; (f) physical agitation, defined as a score higher than 5 on the Sedation-Agitation Scale [6]; and (g) administration of exogenous catecholamines other than low-dose dopamine $\left(2 \mu \mathrm{g} \mathrm{kg}^{-1} \mathrm{~min}^{-1}\right)$. Each of these items was assigned one point if present, none if absent. Hence the minimum score was 0 , and the maximum 7 .

These stress categories were based on the rationale of a known association of the various parameters with both severity of critical illness and increased metabolic demand. Changes in body temperature, heart rate, arterial pressure and respiratory rate are physiological parameters used to determine the Acute Physiology and Chronic Health Evaluation (APACHE) II score [7, 8] which have been validated as markers of the severity of critical illness. Likewise, infection [9], physical agitation [10], and administration of exogenous cathecholamines [11] have all been shown to increase metabolic activity in ICU patients. At our hospital none of the patients are intubated with etomidate, which is known to have an effect on the adrenal function in patients with septic shock. On the other hand, the levels of stress hormones decrease with sedation.

On the basis of the assigned points, patients were categorized into three groups: high stress, those with 4 points or more; moderate stress, 2 or 3 points; low stress, 1 point. APACHE II score was also calculated for all the patients [7]. In addition, all treatments (type, doses, and duration) were recorded.

Catabolic and anabolic hormones

Abnormal plasma levels (high cortisol and glucagon, GH, and insulin; low IGF-1) were used as reference method. Normal values were: insulin 5-18 mU/l; glucagon $42-$ $111 \mathrm{ng} / \mathrm{l}$; IGF-1, age-dependent; GH less than $10 \mu \mathrm{g} / \mathrm{l}$; cortisol 200-700 nmol/l.

Plasma samples drawn from the indwelling radial artery catheter were prepared between 8 and 10 a.m. on days 0 and 3 and frozen at $30^{\circ} \mathrm{C}$ for subsequent determinations of insulin (Imulite 2000 Insulin, Diagnostic Products), coefficient of variation (CV) intra-assay $(8.3 \%)$ and interassays (8.6\%); glucagon (RIA Linco Research), CV intra-assay (5.4\%) and interassays (7.9\%); IGF-1 (Nichols Institute Diagnostics), CV intra-assay (2.4\%) and interassays (5.2\%); GH (Imulite $2000 \mathrm{hGH}$, Diagnostic Products), CV intra-assays (4.6\%) and interassay (5.7\%); and cortisol (Imulite 2000 Cortisol), CV
Table 2 Evolution of clinical assessment of stress in 88 ICU patients on days 0 and 3 after admission using seven clinical parameters

\begin{tabular}{lllr}
\hline Stress category day 0 & $n$ & Stress category day $3 *$ & $n$ \\
\hline High & 27 & High & 19 \\
& & Moderate & 4 \\
\multirow{2}{*}{ Moderate } & Low & 4 \\
& 33 & High & 1 \\
Low & Moderate & 17 \\
& & Low & 15 \\
& 28 & High & 0 \\
& & Moderate & 0 \\
& & Low & 28 \\
\hline
\end{tabular}

$* p<0.001$ vs. day $0\left(\chi^{2}=-3: 76.4,4\right.$ d.f. $)$

intra-assay (5.3\%) and interassays (7.2\%). Laboratory results for routine blood chemistry (e.g., glucose, sodium) were noted on a daily basis.

\section{Statistical analysis}

Results are expressed as mean \pm standard deviation for normally distributed parameters. The differences between stress groups analyzed by analysis of variance using Statview 5.0. Multiple comparisons were evaluated by Bonferroni's method. Nonnormally distributed parameters were expressed as median and range, and patient groups were compared using the Kruskall-Wallis test for overall analysis and Mann-Whitney nonparametric test for unpaired samples for intergroup analysis. Pearson's correlation coefficient values were determined between clinical stress category and hormone levels. Logistic regressions were used to estimate odds ratios (OR) for various stress categories. OR with $95 \%$ confidence intervals (CI) describe the magnitude of effects for each level of the study variable compared with the reference category. Statistical significance was set at $p \leq 0.05$ for all tests.

\section{Results}

Patients

Table 2 shows that four patients classified as high stress on day 0 were classified as moderate stress on day 3 and four as low stress at day 3 . One moderate stress patient was classified as high stress on day 3 , and 15 moderate stress patients became low stress on day 3. None of the low stress patients at admission changed stress category on day 3. Serum glucose and osmolarity were significantly higher and serum protein was significantly lower in high-stress than in low-stress patients on days 0 and 3 (Table 3). Serum potassium, blood urea nitrogen, and creatinine did not differ significantly between patient groups. 
Table 3 Laboratory parameters by patient stress categories on days 0 and 3

\begin{tabular}{|c|c|c|c|}
\hline \multirow[t]{2}{*}{ Day 0} & \multirow{2}{*}{$\frac{\text { Severe }}{n=27}$} & \multirow{2}{*}{$\frac{\text { Moderate }}{n=33}$} & \multirow{2}{*}{$\frac{\text { Low }}{n=28}$} \\
\hline & & & \\
\hline Glucose (mmol/l) & $10.7 \pm 4.1$ & $8.2 \pm 3.6^{*}$ & $6.9 \pm 2.3 *$ \\
\hline Sodium (mmol/l) & $138.0 \pm 4.8$ & $138.5 \pm 5.4$ & $137.5 \pm 4.1$ \\
\hline Potassium $(\mathrm{mmol} / \mathrm{l})$ & $3.8 \pm 0.5$ & $4.1 \pm 0.6$ & $3.9 \pm 0.3$ \\
\hline Protein $(\mathrm{g} / \mathrm{l})$ & $62.9 \pm 10.0$ & $64.4 \pm 6.3$ & $67.6 \pm 5.9$ \\
\hline $\begin{array}{l}\text { Blood urea nitrogen } \\
(\mathrm{mmol} / \mathrm{l})\end{array}$ & $9.9 \pm 5.7$ & $10.8 \pm 6.1$ & $8.3 \pm 8.4$ \\
\hline Creatinine $(\mathrm{mmol} / \mathrm{l})$ & $116.4 \pm 49.1$ & $112.2 \pm 50.4$ & $92.9 \pm 25.5$ \\
\hline $\begin{array}{l}\text { Osmolarity } \\
(\mathrm{mmol} / \mathrm{kg})\end{array}$ & $294.2 \pm 14.0$ & $293.7 \pm 11.5$ & $287.8 \pm 8.0$ \\
\hline Day 3 & $n=20$ & $n=21$ & $n=47$ \\
\hline Glucose $(\mathrm{mmol} / \mathrm{l})$ & $10.2 \pm 3.8$ & $9.0 \pm 3.3^{*}$ & $6.8 \pm 2.2 * * *$ \\
\hline Sodium $(\mathrm{mmol} / \mathrm{l})$ & $141.9 \pm 5.4$ & $138.9 \pm 4.8$ & $138.6 \pm 4.7 *$ \\
\hline Potassium (mmol/l) & $4.1 \pm 0.3$ & $4.2 \pm 0.5$ & $3.9 \pm 0.3$ \\
\hline Protein $(\mathrm{g} / \mathrm{l})$ & $60.9 \pm 6.4$ & $61.9 \pm 9.3$ & $66.0 \pm 6.3^{*}$ \\
\hline $\begin{array}{l}\text { Blood urea nitrogen } \\
(\mathrm{mmol} / \mathrm{l})\end{array}$ & $10.4 \pm 6.6$ & $16.1 \pm 30.7$ & $8.2 \pm 5.6$ \\
\hline Creatinine $(\mathrm{mmol} / \mathrm{l})$ & $104.4 \pm 46.7$ & $97.4 \pm 66.4$ & $110.2 \pm 75.8$ \\
\hline $\begin{array}{l}\text { Osmolarity } \\
(\mathrm{mmol} / \mathrm{kg})\end{array}$ & $301.8 \pm 17.2$ & $295.8 \pm 11.9$ & $290.9 \pm 14.6 *$ \\
\hline
\end{tabular}

$* p \leq 0.05$ vs. moderate- or low-stress (analysis of variance), ${ }^{* *} p \leq 0.05$ vs. moderate- and low-stress (post-hoc Bonferroni's test after one-factor analysis of variance)

\section{Plasma hormone concentrations}

Insulin levels did not differ significantly between stress categories on days 0 or 3 (Table 4). Glucagon, cortisol, and GH were higher and IGF-1 lower in high-stress than in low-stress patients $(p<0.01$; Table 4$)$. Levels of these hormones were correlated with the clinical stress category $(p<0.05$; Table 5). Stepwise multiple regressions including age, cortisol, glucagon, IGF-1, GH, and insulin showed that cortisol and IGF-1 were significant predictors of the clinical stress category $(p<0.001)$ and explained $27 \%$ of the variability. The prevalence of high glucagon and cortisol and low IGF-1 was significantly greater in high-stress than in low-stress patients. High-stress pa- tients were more likely to have high glucagon $(p<0.01)$ and cortisol $(p<0.05)$ and low IGF-1 $(p<0.01)$ levels than low stress patients (Table 6). Insulin and GH were not associated with high stress level.

\section{Discussion}

The results of this study show that moderate and severe stress is significantly associated with high catabolic (cortisol, glucagon) and low anabolic (IGF-1) hormone levels. We found a significant association between these hormone levels and seven routine clinical parameters (e.g., heart rate, fever, presence of infection), which suggests that the levels of hormonal stress in medical ICU patients can be estimated from simple clinical parameters during routine clinical evaluation.

Patient characteristics and stress category classification

The patient population represented a wide range of ages and included a representative sample of usual conditions found in medical ICU patients. The attending physician classified each patient included in the study protocol as having low, moderate, or high stress at the time of ICU admission and reclassified the patient after 3 days. The significant association between simple clinical parameters and catabolic (glucagon, cortisol) and anabolic hormone levels (IGF-1) suggests that the hormonal stress state of ICU patients can be determined by these simple clinical parameters. Rapid clinical assessment of stress state would be desirable in view of the poor clinical outcome in patients who have high hormonal stress levels and are malnourished at the same time [12]. Early detection of increased risk would permit timely clinical intervention in patients who are at high stress level or malnourished at the time of ICU admission.

Table 4 Plasma hormone levels measured on day 0 and 3 after admission to the ICU

\begin{tabular}{|c|c|c|c|c|c|c|c|}
\hline & \multicolumn{3}{|l|}{ Stress category } & \multirow{2}{*}{$\begin{array}{l}\text { Kruskal- } \\
\text { Wallis }\end{array}$} & \multicolumn{3}{|c|}{$p$ (Mann-Whitney) } \\
\hline & High & Moderate & Low & & $\begin{array}{l}\text { High vs. } \\
\text { moderate }\end{array}$ & $\begin{array}{l}\text { Moderate } \\
\text { vs. low }\end{array}$ & $\begin{array}{l}\text { High } \\
\text { vs. low }\end{array}$ \\
\hline \multicolumn{8}{|l|}{ Day 0} \\
\hline Insulin (mU/l) & $27.3(4-585)$ & $36.8(8-178)$ & $26.1(4-189)$ & 0.520 & 0.377 & 0.297 & 0.960 \\
\hline Glucagon (ng/l) & $116(36-801)$ & $105(33-2216)$ & $64(35-181)$ & $<0.001$ & 0.513 & $<0.001$ & $<0.001$ \\
\hline Cortisol (nmol/l) & 854 (231-1784) & 806 (222-1968) & $499(174-1285)$ & 0.001 & 0.427 & 0.003 & 0.001 \\
\hline IGF-1 $(\mu \mathrm{g} / \mathrm{l})$ & $34.9(13-141)$ & $53.9(11-217)$ & $78.9(22-147)$ & $<0.001$ & 0.019 & 0.105 & $<0.001$ \\
\hline $\mathrm{GH}(\mu \mathrm{g} / \mathrm{l})$ & $1.2(0.2-36.5)$ & $0.6(0.0-12.3)$ & $0.4(0.2-7.8)$ & 0.025 & 0.099 & 0.142 & 0.011 \\
\hline \multicolumn{8}{|l|}{ Day 3} \\
\hline Insulin (mU/l) & $53(9-289)$ & $39(8-193)$ & $36(7-245)$ & 0.585 & 0.419 & 0.801 & 0.331 \\
\hline Glucagon (ng/l) & $209(45-1223)$ & $119(51-2394)$ & $82(32-940)$ & $<0.001$ & 0.054 & 0.020 & $<0.001$ \\
\hline Cortisol (nmol/l) & 786 (329-1932) & $708(321-1956)$ & $565(71-1217)$ & 0.020 & 0.230 & 0.144 & 0.008 \\
\hline IGF-1 $(\mu \mathrm{g} / \mathrm{l})$ & $39(13-163)$ & $51(13-115)$ & $72(11-179)$ & 0.005 & 0.179 & 0.139 & 0.001 \\
\hline $\mathrm{GH}(\mu \mathrm{g} / \mathrm{l})$ & $2.8(0.2-24.8)$ & $1.4(0.2-9.5)$ & $0.5(0.2-6.8)$ & $<0.001$ & 0.315 & 0.003 & $<0.001$ \\
\hline
\end{tabular}


Table 5 Statistical significance of simple correlations between hormone levels and stress category measured on days 0 and 3 after admission to the ICU. Normal laboratory values: insulin 5-18 mU/ 1; glucagon 42-111 ng/l; insulin-like growth factor 1 (IGF-1); growth hormone $(G H)<10 \mu \mathrm{g} / \mathrm{l}$; cortisol 200-700 nmol/l

\begin{tabular}{lrrrrr}
\hline & Day 0 & & \multicolumn{2}{c}{ Day 3} & \\
\cline { 2 - 3 } & \multicolumn{1}{c}{$r$} & \multicolumn{1}{c}{$p$} & & \multicolumn{1}{c}{$p$} \\
\hline Insulin & 0.078 & 0.472 & & 0.110 & 0.284 \\
Glucagon & 0.228 & 0.033 & & 0.261 & 0.014 \\
IGF-1 & -0.395 & $<0.001$ & & -0.438 & $<0.001$ \\
GH & 0.290 & 0.006 & & 0.336 & 0.001 \\
Cortisol & 0.383 & $<0.001$ & & 0.365 & $<0.001$ \\
\hline
\end{tabular}

The aim of this stress classification was not to predict mortality, as with APACHE II or III scores, but to evaluate the relationship between stress and plasma hormonal stress. The stress classification allows the evaluation of the level of hormonal stress and thus catabolism and helps to identify patients needing early nutritional support without using labor- and cost-intensive investigations. Consequently the APACHE II or III scores and the stress classification do not have the same aim, are not intended to be used interchangeably, and cannot be compared.

Relevance of plasma hormone measurements for hormonal stress assessment

Our goal was primarily to assess the degree of catabolism in ICU patients by a clinical stress category which was based on simple clinical parameters. The level of hor- monal stress was assessed objectively by measuring plasma levels of stress hormones, as previously reported by others [13, 14, 15]. In hypermetabolic conditions glucocorticosteroids play a major role in the loss of body protein in acute catabolic disease by increasing proteolysis and amino acid oxidation and by decreasing the efficacy of insulin to suppress proteolysis $[16,17]$.

Hypermetabolism and hypercatabolism are also mediated by proinflammatory cytokines, which have been shown to cause muscle protein breakdown. On the other hand, GH, IGF-1, and insulin levels have been shown to be correlated to decreased proteolysis and amino acid oxidation and to an increase in whole body protein synthesis $[16,17]$. Therefore five of the most potent plasma hormonal factors which regulate protein metabolism $(\mathrm{GH}$, IGF-1, insulin, cortisol, and glucagon) known to vary in response to hormonal stress were measured and compared in relation to clinical parameters. IGF-1, glucagon, and cortisol plasma levels were found to be better determinants of hormonal stress than $\mathrm{GH}$, and insulin was not at all correlated with the three stress levels (Table 4). Plasma cortisol levels increase with severity of stress [18] and has been shown to be the best hormonal predictor of the degree of lean body mass catabolism [19]. Cortisol is a major determinant in the hormonal stress, and glucocorticoid administration can influence plasma cortisol values. Six patients received $200-300 \mathrm{mg} /$ day hydrocortisone (four high, one moderate, one low stress); seven received 100-200 mg/day (two high, four moderate, one low stress); and six received less than $100 \mathrm{mg} /$ day (one high, four moderate, one low stress). We therefore performed a post-hoc analysis to exclude patients who received glu-

Table 6 Odds ratio (95\% CI) for abnormal, vs. normal, plasma hormone concentrations, adjusted for age, for patients with moderate or high vs. low stress category. Logistic regressions, adjusted

for age; normal laboratory values: glucagon 42-111 ng/l; insulinlike growth factor-1 (IGF-1) age-dependent; cortisol 200$700 \mathrm{nmol} / \mathrm{l}$

\begin{tabular}{|c|c|c|c|c|c|c|c|c|c|c|}
\hline \multirow[t]{2}{*}{ Stress } & \multicolumn{5}{|l|}{ Day 0} & \multicolumn{5}{|l|}{ Day 3} \\
\hline & $\begin{array}{l}\text { Low } \\
\text { value }\end{array}$ & $\begin{array}{l}\text { Normal } \\
\text { value }\end{array}$ & $\begin{array}{l}\text { High } \\
\text { value }\end{array}$ & $\begin{array}{l}\text { OR }(95 \% \mathrm{CI}) \\
\text { adjusted for } \\
\text { age }\end{array}$ & $p$ & $\begin{array}{l}\text { Low } \\
\text { value }\end{array}$ & $\begin{array}{l}\text { Normal } \\
\text { value }\end{array}$ & $\begin{array}{l}\text { High } \\
\text { value }\end{array}$ & $\begin{array}{l}\text { OR }(95 \% \mathrm{CI}) \\
\text { adjusted for } \\
\text { age }\end{array}$ & $p$ \\
\hline \multicolumn{11}{|l|}{ Cortisol } \\
\hline Low & - & $18(64.3 \%)$ & $10(35.7 \%)$ & 1 & & - & $30(63.8 \%)$ & $17(36.2 \%)$ & 1 & \\
\hline Moderate & - & $12(36.4 \%)$ & $21(63.6 \%)$ & $3.4(1.2-9.9)$ & 0.026 & - & $10(47.6 \%)$ & $11(52.4 \%)$ & $2.1(0.7-6.2)$ & 0.172 \\
\hline High & - & $7(25.9 \%)$ & $20(74.1 \%)$ & $5.8(1.8-18.9)$ & 0.004 & - & $7(35.0 \%)$ & $13(65.0 \%)$ & $3.3(1.1-10.0)$ & 0.033 \\
\hline \multicolumn{11}{|l|}{ Glucagon } \\
\hline Low & - & $25(89.3 \%)$ & $3(10.7 \%)$ & 1 & & - & $37(78.7 \%)$ & $10(21.3 \%)$ & 1 & \\
\hline Moderate & - & $18(54.5 \%)$ & $15(45.5 \%)$ & $6.9(1.7-27.5)$ & 0.006 & - & $9(42.9 \%)$ & $12(57.1 \%)$ & $4.5(1.4-13.8)$ & 0.010 \\
\hline High & - & $13(48.1 \%)$ & $14(51.9 \%)$ & $8.7(2.1-36.1)$ & 0.003 & - & $3(15.05 \%)$ & $17(85.0 \%)$ & $21.8(5.2-91.2)$ & $<0.001$ \\
\hline \multicolumn{11}{|l|}{ IGF-1 } \\
\hline Low & $\begin{array}{c}9 \\
(32.1 \%)\end{array}$ & $19(67.9 \%)$ & - & 1 & & $\begin{array}{l}18 \\
(38.3 \%)\end{array}$ & $29(61.7 \%)$ & - & 1 & \\
\hline Moderate & $\begin{array}{l}16 \\
(48.5 \%)\end{array}$ & $17(51.5 \%)$ & - & $1.9(0.7-5.6)$ & 0.217 & $\begin{array}{l}13 \\
(61.9 \%)\end{array}$ & $8(38.1 \%)$ & - & $3.6(1.2-11.2)$ & 0.025 \\
\hline High & $\begin{array}{l}20 \\
(74.1 \%)\end{array}$ & $7(25.9 \%)$ & - & $5.9(1.8-19.0)$ & 0.003 & $\begin{array}{l}15 \\
(75.0 \%)\end{array}$ & $5(25.0 \%)$ & - & $5.5(1.6-19.3)$ & 0.006 \\
\hline
\end{tabular}


cocorticoids either chronically or acutely (asthma, chronic obstructive pulmonary disease, $n=19$ ) but the predictive significance of the stress levels remained unchanged (data not shown). Although free cortisol appears to be a better marker of adrenal function in ICU patients with hypoproteinemia than total cortisol levels, as suggested by Hamrahian et al. [20], total cortisol was measured as this still represents the reference method in routine clinical practice.

Age and sex have recently been reported to influence plasma levels of IGF-1 in trauma patients and during the postoperative period [21], but this was not found in our patients with a different type of stress (medical ICU). Our previous study of nonsurgical ICU patients observed wide variations in IGF-1 without any relationship to age and sex distribution [22]. These discrepancies may be related to confounding factors such as IGF-1 receptors and binding protein changes secondary to stress and which alter plasma availability of free IGF-1 [23].

GH secretion during stress becomes erratic [24], and plasma sampling results are influenced by timing [22]. Therefore we also measured 24-h urinary GH output in all patients with the hope of assessing overall GH secretion. The correlation between clinical stress category and urinary GH was poor (data not shown), and this further supports our observation that plasma GH is not associated with stress levels in medical ICU patients.

\section{Study limitations}

This is a pilot study, and our findings require further validation. The study was conducted in the medical ICU and included a typical case-mix for such a unit. Therefore any extrapolation to a general ward patient population remains speculative, given that these patients were not studied here. A limitation of the study is that the individual parameters included in the stress score were not documented, only the overall stress score. Therefore stepwise multiple regression analysis could not be performed to determine which parameters contributed significantly to the stress score. Future studies should include this analysis. Because patients with preexisting renal failure, insulin-treated type 2 diabetes, adrenal or thyroid insufficiency, and neuromuscular disease were excluded from the study, the applicability of the present stress categories in these patients remains to be determined. Glucose-containing nutritional support and DW5 perfusion alters insulin and glucagon plasma levels. In spite of this the correlation between anabolic or catabolic hormone levels and the clinical stress category remained similar. Measurement of 24-h urinary output of catecholamines, which was not performed, may have yielded additional information on stress level. However, the fact that most of the patients in the severe stress group received exogenous doses of catecholamines would have interfered with the interpretation of these results.

\section{Conclusion}

The clinical scoring of moderate and severe stress was significantly associated with high catabolic (cortisol, glucagon) and low anabolic (IGF-1) hormone levels. These results suggest that the level of hormonal stress in ICU patients can be estimated from simple clinical parameters during routine clinical evaluation. Since nutritional support is one of the therapeutic strategies to limit catabolism, its timely application in proportion to the stress level is desirable. Further research is necessary to determine whether this method facilitates the decision to implement nutritional support in ICU patients.

Acknowledgements We are indebted to R.C. Gaillard, E. Temler, F. Ray, and M.C. Burnier for preparing and measuring some of the biological samples.

\section{References}

1. Griffiths RD (1996) Muscle mass, survival, and the elderly ICU patient. Nutrition 12:456-458

2. Anonymous (1977) Taber's cyclopedic medical dictionary. Davis: Philadelphia

3. Jolliet P, Pichard C, Biolo G, Chioléro R, Grimble G, Leverve X, Nitenberg G, Novak I, Planas M, Preiser JC et al (1998) Enteral nutrition in intensive care patients: a practical approach. A position paper. Intensive Care Med 24:848-859
4. Isenring EA, Capra S, Bauer JD (2004) Nutrition intervention is beneficial in oncology outpatients receiving radiotherapy to the gastrointestinal or head and neck area. Br J Cancer 91:447-452

5. Berard MP, Zazzo JF, Condat $\mathrm{P}$, Vasson MP, Cynober L (2000) Total parenteral nutrition enriched with arginine and glutamate generates glutamine and limits protein catabolism in surgical patients hospitalized in intensive care units. Crit Care Med 28:3637-3644

6. Riker RR, Picard JT, Fraser GL (1999) Prospective evaluation of the SedationAgitation Scale for adult critically ill patients. Crit Care Med 27:1325-1329
7. Knaus WA, Draper EA, Wagner DP, Zimmerman JE (1986) APACHE II: a severity of disease classification system. Crit Care Med 13:818-829

8. Le Gall JR, Lemeshow S, Saulnier F (1993) A new Simplified Acute Physiology Score (SAPS II) based on a European/North American multicenter study. JAMA 270:2957-2963

9. Moriyama S, Okamoto K, Tabira Y, Kikuta K, Kukita I, Hamaguchi M, Kitamura N (1999) Evaluation of oxygen consumption and resting energy expenditure in critically ill patients with systemic inflammatory response syndrome. Crit Care Med 27:2133-2136 
10. Terao Y, Miura K, Saito M, Sekino M, Fukusaki M, Sumikawa K (2003) Quantitative analysis of the relationship between sedation and resting energy expenditure in postoperative patients. Crit Care Med 31:830-833

11. Schaffartzik W, Sanft C, Schaefer JH, Spies C (2000) Different dosages of dobutamine in septic shock patients: determining oxygen consumption with a metabolic monitor integrated in a ventilator. Intensive Care Med 26:1740-1746

12. Griffiths RD (2003) Nutrition support in critically ill septic patients. Curr Opin Clin Nutr Metab Care 6:203-210

13. Roth-Isigkeit A, Brechmann J, Dibbelt L, Sievers HH, Raasch W, Schmucker P (1998) Persistent endocrine stress response in patients undergoing cardiac surgery. J Endocrinol Invest 21:12-19

14. Wray CJ, Mammen JM, Hasselgren PO (2002) Catabolic response to stress and potential benefits of nutrition support. Nutrition 18:971-977

15. Nguyen NT, Goldman CD, Ho HS, Gosselin RC, Singh A, Wolfe BM (2002) Systemic stress response after laparoscopic and open gastric bypass. J Am Coll Surg 194:557-566-
16. Gore DC, Wolf SE, Sanford AP, Herndon DN, Wolfe RR (2004) Extremity hyperinsulinemia stimulates muscle protein synthesis in severely injured patients. Am J Physiol Endocrinol Metab 286:E529-E534

17. Carroll PV, Jackson NC, Russell-Jones DL, Treacher DF, Sonksen PH, Umpleby AM (2004) Combined growth hormone/insulin-like growth factor I in addition to glutamine-supplemented TPN results in net protein anabolism in critical illness. Am J Physiol Endocrinol Metab 286:E151-E157

18. Span LF, Hermus AR, Bartelink AK, Hoitsma AJ, Gimbrere JS, Smals AG, Kloppenborg PW (1992) Adrenocortical function: an indicator of severity of disease and survival in chronic critically ill patients. Intensive Care Med 18:9396

19. Arnold J, Campbell I, Samuels I, Devlin J, Green C, Hipkin L, MacDonald I, Scrimgour C, Smith K, Rennie M (1993) Increased whole body protein breakdown predominates over increased whole body protein synthesis in multiple organ failure. Clin Sci (Lond) 84:655-661
20. Hamrahian AH, Oseni TS, Arafah BM (2004) Measurements of serum free cortisol in critically ill patients. N Engl J Med 350:1629-1638

21. Houston-Bolze MS, Downing MT, Sayed AM, Williford JH (1996) Gender differences in the responses of serum insulin-like growth factor and transthyretin (prealbumin) to trauma. Crit Care Med 24:1982-1987

22. Pichard C, Kyle U, Chevrolet JC, Jolliet P, Slosman D, Mensi N, Temler E, Ricou B (1996) Lack of effects of recombinant growth hormone on muscle function in patients requiring prolonged mechanical ventilation: a prospective randomized controlled study. Crit Care Med 24:403-413

23. Houston-Bolze MS, Downing MT, Sayed AM, Williford JH (1996) Serum insulin-like growth factor binding protein-3 responds differently to trauma in men and women. Crit Care Med 24:1988-1992

24. Van den Berghe G, Baxter RC, Weekers F, Wouters P, Bowers CY, Veldhuis JD (2000) A paradoxical gender dissociation within the growth hormone/insulin-like growth factor I axis during protracted critical illness. J Clin Endocrinol Metab 85:183-192 